\title{
A EDUCAÇÃO COMO INSTRUMENTO NA CONSTRUÇÃO DA CONSCIÊNCIA AMBIENTAL
}

\author{
COSTA, Cristiane Aparecida da ${ }^{1}$ \\ COSTA, Fabiana Gorricho ${ }^{2}$
}

\begin{abstract}
RESUMO: A Educação Ambiental é uma necessidade da sociedade atual e da realidade em que se encontra o planeta. A preocupação com o meio ambiente vem crescendo a cada dia e com isso a busca para desenvolver meios para reverter ou minimizar efeitos causados pelas ações da humanidade ao longo dos tempos. Mas isso será possível quando se desenvolver no indivíduo a conscientização, a sensibilização, a percepção de tudo o que ocorre ao seu redor. Sendo a educação o caminho mais propício para que essa mudança ocorra, e o alicerce da vida de qualquer ser humano, na construção de um cidadão consciente, ativo e participativo na sociedade. Essa pesquisa teve como objetivo verificar o desenvolvimento da educação ambiental nas escolas, sua importância para os professores, para os alunos e como ela é percebida pelos mesmos. Para a sua realização foi pesquisada em duas escolas públicas e estaduais. A pesquisa realizada foi de caráter investigativo, sendo uma pesquisa qualitativa aplicada através de questionários que foram coletados e analisados pela pesquisadora. Foi possível constatar que as escolas possuem educação ambiental apoiadas em projetos de empresas da cidade e da FAFRAM, assim como a realização de alguns projetos da Secretaria do Estado. E mesmo possuindo algumas práticas de educação ambiental, muitas ficam restritas apenas à comunidade escolar, mas foi constatado que os alunos já possuem certa percepção das questões ambientais, da mesma maneira que sensibilidade e começam a ter conscientização das suas atitudes e dos problemas ambientais.
\end{abstract}

Palavras-chave: Ensino. Educação ambiental. Conscientização.

SUMMARY: Environmental education is a necessity of society and current reality in which lies the planet. The concern for the environment has been growing day and that the quest to develop means to reverse or minimize the effects caused by the actions of mankind throughout the ages. But it will be possible when developing the individual awareness, sensibility, perception of everything that happens to your around. Since education is the path most conducive to that change happen, and the foundation of life any human being, to build a citizen conscious, active and participatory society. This research focuses on the development of education environment and its importance in student life. For their achievement were investigated in two schools public and state the importance of environmental education for teachers and students, and how it is perceived by them. The survey was conducted of character investigative, and applied a qualitative research through questionnaires that were collected and analyzed by the researcher. It was possible to see that schools are supported by environmental education projects and businesses in the city and in the FAFRAM, as well as the completion of some projects of the Department of State. And even if they have some education practices Environmental many are restricted only to community school, but it was found that students already possess a certain perception of environmental issues, the same way sensitivity and begin to have awareness of their attitudes and problem environment.

Keywords: Education. Environmental education. Awareness.

\footnotetext{
1 Graduada em Pedagogia pela Faculdade de Filosofia, Ciências e Letras de Ituverava-SP. Contato: cristtycosta@gmail.com

${ }^{2}$ Professora Mestre da Faculdade de Filosofia, Ciências e Letras de Ituverava-SP e orientadora do Trabalho de Conclusão de Curso. Contato: fabianagorricho@feituverava.com.br
} 


\section{INTRODUÇÃO}

A educação é o caminho mais propício para a socialização do indivíduo e para a transformação da sociedade. Ela é fundamental no desenvolvimento humano em todas as suas dimensões: cognitivas, afetivas e sociais.

A educação é o agente de mudanças de novas descobertas, de novos paradigmas que vão sendo construídos à medida que se vai conhecendo e tendo o acesso as informações.

O aprendizado ocorre a todo instante. A cada momento há uma nova oportunidade de se aprender.

Nos dias atuais, observa-se uma sociedade carente e necessitada de respeito, dignidade, qualidade de vida, moradia, emprego entre outros. E uma sociedade irresponsável, consumista que tem se manifestado através dos seus atos, causando a insustentabilidade do planeta. Sendo assim, a educação é vista como instrumento para a construção de um cidadão consciente, participativo e responsável. E a educação ambiental é posta como o processo de transformação de valores sociais, de conhecimento, novas atitudes voltadas para a conservação do ambiente e construção da conscientização ambiental.

Muito se fala em maneiras para reverter os danos causados ao planeta. No decorrer da história da humanidade, percebe-se que o relacionamento do homem com a natureza foi de exploração, sem se preocupar com o que poderia ocorrer consequentemente.

A educação ambiental quer desenvolver no indivíduo a compreensão de que ele é parte fundamental do meio ambiente, causando o bem ou o mal ao planeta e que suas práticas e atitudes podem transformar ou destruir o planeta, preservar a vida ou extingui-la. E é através de sua consciência que suas atitudes serão tomadas de forma eficaz.

A educação ambiental é algo que se faz necessário à realidade de qualquer pessoa, inclusive das crianças, pois quando mais cedo formar no ser humano, maior será a sua consciência ambiental e social.

A escolha do tema se deu devido a importância que a educação ambiental tem na vida das pessoas e na manutenção do planeta e de como a educação é a mediadora de conhecimentos e pode transformar toda a sociedade.

A problemática desse trabalho surgiu através da necessidade de se conscientizar a sociedade para as questões ambientais. E o que fazer para que a conscientização ambiental ocorra e como desenvolver a percepção e a sensibilização sobre aspectos tão importantes como economia, política, ecologia, sociais e ambientais tão necessários para a realidade em que se encontra o planeta. 
Muito se falam sobre preservação, reciclagem, práticas ambientalmente corretas, sustentabilidade, entre outros. Entretanto, é necessário desenvolver no indivíduo a conscientização, a sensibilização e a percepção, para que suas atitudes não sejam algo superficial, mecânico sem se dar a real valoração nas suas atitudes e em seu comportamento.

Se desenvolver a conscientização ambiental na criança, ela certamente será um indivíduo ativo na sociedade.

Para a elaboração deste trabalho foi realizado um levantamento bibliográfico a respeito do tema, e depois desenvolvido uma pesquisa de caráter investigativo qualitativo em duas instituições de ensino públicas e estaduais da cidade de São Joaquim da Barra, a fim de diagnosticar a prática de educação ambiental.

No primeiro momento da pesquisa foi realizado um levantamento de perfis ambientais das instituições de ensino público em seguida distribuído questionários nas duas instituições, para a análise de investigativa sobre como se realiza a educação ambiental no seu dia a dia.

\section{EDUCAÇÃO AMBIENTAL}

De acordo com a Conferência Intergovernamental sobre Educação Ambiental, em Tbilisi, (1977), educação ambiental "é o resultado de uma reorientação e articulação de diversas disciplinas e experiências educativas que facilitam a percepção integrada do meio ambiente, tornando possível uma ação mais racional e capaz de responder as necessidades sociais".

A Educação Ambiental então seria uma forma de prática educacional sintonizada com a vida da sociedade, e o comportamento do homem e sua relação com o meio ambiente, suas habilidades e suas percepções.

Segundo Dias, (2004, p.148) educação ambiental:

[...] é considerada um processo permanente pelo qual o indivíduo e a comunidade tomam consciência do seu meio ambiente e adquirem o conhecimento, os valores, as habilidades, as experiências e a determinação que os torna aptos a agir individual e coletivamente - e resolver problemas ambientais presentes e futuros.

Sendo assim, a Educação Ambiental deve promover formas de percepção e compreensão dos fatores que interagem no tempo e no espaço, na vida e nas suas perspectivas, permitindo assim ao homem, definir valores e motivações que o conduz a padrões de comportamento de preservação, conscientização e melhoria do meio ambiente, e uma melhor qualidade de vida. 
De acordo com Dias (2004), deve também abranger os aspectos sociais, culturais, físicos e biológicos, pois estão relacionados com o meio natural do homem e como se dão suas relações na sociedade, permitindo aos indivíduos e grupos sociais ampliarem a sua percepção e internalizarem conscientemente a necessidade de mudanças.

O despertar da consciência ecológica, princípio e fïm de uma educação ambiental, é substanciada por uma razão crítica, que percebe as relações de poder de caráter dominador e explorador, que desestruturam, que rompem laços, produzem cisão, que degradam homem e natureza. Assim como, reciprocamente, deve substanciar-se pela provocação do sentimento de pertencimento solidário, o que interconecta, o que integra unidade e multiplicidade. (GUIMARÃES, 2088, p. 99).

A Educação Ambiental se interliga em um contexto social, econômico, ecológico e cultural e está interligada a todos esses aspectos.

De acordo com Dias (2004), é necessário que se conheçam cada um destes aspectos para que a Educação Ambiental seja feita de forma eficaz. A realidade de cada indivíduo, sociedades e suas relações com o meio ambiente devem ser consideradas e analisadas.

As pessoas independentes, de suas condições sociais devem ter a percepção do que é Educação Ambiental, dos problemas ambientais que ocorrem no seu dia a dia, tendo em mente que a temática envolve questões culturais, sociais, ecológicas, econômicas e políticas, e que todos são responsáveis por suas ações e reações. E que é impossível se falar em educação ambiental sem levar em consideração esses fatores. Tem como finalidade despertar as pessoas do senso comum, conscientizando-as que suas mazelas dependem também das ações políticas e econômicas.

Os Parâmetros Curriculares Nacionais - Meio Ambiente e Saúde (1997, p.22), esclarece também que a educação ambiental é uma necessidade da civilização atual que busca solucionar as suas crises: ${ }^{3}$

Para outros a questão ambiental representa quase uma síntese de impasses que o atual modelo de civilização acarreta. Consideram que aquilo a que se assiste, no final do século XX, não é só uma crise ambiental, mas uma crise civilizatória. É que a superação dos problemas exigirá mudanças profundas na concepção de mundo, de natureza, de poder, de bem-estar, tendo por base novos valores individuais e sociais.

Segundo Dias (2004), pode-se dizer que os conceitos de educação ambiental que antes eram voltados apenas à área de ecologia e trabalhados apenas nas aulas de Ciências evoluíram na medida em que o meio ambiente passou a ser percebido e passou a ter um enfoque interdisciplinar, como o homem se relaciona com o meio ambiente em todos os aspectos, como o ser humano depende dele, como o afeta e como promove sua sustentabilidade.

\footnotetext{
${ }^{3}$ Em alguns momentos será utilizada a sigla PCN para Parâmetros Curriculares Nacionais. Nucleus, v.8, n.2, out.2011
} 
A Constituição Brasileira de 1988 considera a temática ambiental em diversos pontos onde se destaca o Cap. VI do Meio Ambiente, Art. 225, na qual todos têm direito ao meio ambiente ecologicamente equilibrado, bem de uso comum do povo e essencial à sadia qualidade de vida, impondo-se ao poder público e à coletividade o dever de defendê-lo e preservá-lo para as presentes e futuras gerações.” Destaca-se ainda o parágrafo $3^{\circ}$ do mesmo artigo:" As condutas e atividades consideradas lesivas ao meio ambiente sujeitarão aos infratores, pessoas físicas ou jurídicas, a sanções penais administrativas, independentemente da obrigação de reparar os danos causados (DIAS, 2004).

De acordo com a Política Nacional do Meio Ambiente, definida por meio da Lei $\mathrm{n}^{\circ}$ 6.983/81, situa a Educação Ambiental como um dos princípios que garantem "a preservação, melhoria e recuperação da qualidade ambiental propicia a vida, visando assegurar no país condições ao desenvolvimento socioeconômico, aos interesses da segurança nacional e à proteção da dignidade da vida humana". E estabelece ainda que a Educação Ambiental deve ser oferecida em todos os níveis de ensino, preparando todo cidadão para a defesa do meio ambiente.

A Lei no 9.795, de 27 de abril de 1999, Cap. I art. $2^{\circ}$ diz que: “A educação ambiental é um componente essencial e permanente da educação nacional, devendo estar presente de forma articulada em todos os níveis e modalidades do processo educativo, em caráter formal e não formal”. O Cap. II art. 10 diz que "a educação ambiental será desenvolvida como uma prática educativa integrada continua e permanente em todos os níveis e modalidades do ensino formal". O art. 13 especifica que "entendem-se por educação ambiental não-formal as ações e práticas educativas voltadas à sensibilização da coletividade sobre as questões ambientais e à sua organização e participação na defesa da qualidade do meio ambiente".

A Educação Ambiental não deve ser entendida como uma disciplina a mais no currículo, mas deve permear todas as áreas do conhecimento deve ser realizada de forma interdisciplinar. A interdisciplinaridade deve ser entendida como uma maneira de organizar e produzir conhecimento, interagindo com as diferentes dimensões dos fenômenos estudados. A educação ambiental e a interdisciplinaridade são práticas que se completam, pois para se entender os problemas ambientais são necessários conhecer diversos aspectos que estão situados na interdisciplinaridade do assunto abordado.

A Educação Ambiental nas escolas vem para transformar a educação tradicional, tornando-a mais ativa, desenvolvendo indivíduos que se preocupam com o meio ambiente, entendendo que o ser humano necessita da natureza para sobreviver e manter o equilíbrio do planeta. 
O aluno é o sujeito do conhecimento. Ou seja: com sua capacidade cognitiva, ele é um agente ativo na apreensão, elaboração e recriação do conhecimento, cabendo ao educador o papel de facilitar este processo... Da mesma forma, as ações educativas junto á sociedade civil também devem estar referenciadas no contexto cultural. Este contexto, abrangendo as práticas e representações da comunidade, inclui os processos de educação formal ali desenvolvidos, à medida que a escola é concebida como espaço da comunidade. (ALVES, 1995, p.29)

É preciso que os indivíduos saibam como interagir um com o outro respeitando as diversidades, analisem seus problemas locais e globais, se relacionarem com o tempo e com espaço, analisando as consequiências que suas atitudes podem ocasionar a curto, médio e longo prazo, e como o homem tem se relacionado com a natureza e como ele pode minimizar ou reverter as suas ações. Mais do que desenvolver cidadãos críticos é desenvolver cidadãos preocupados com o equilíbrio do planeta e com atitudes ambientalmente corretas.

Para que isso ocorra é necessário atingir o ser humano em suas dimensões físicas, psíquicas e emocionais. De acordo com o professor Antonio José Rocha, a Educação Ambiental só é eficiente quando se trabalha três esferas ou domínios. ${ }^{4}$

Esfera cognitiva - é o campo do conhecimento onde a pessoa recebe as informações básicas sobre os temas que estão sendo trabalhados, sobre a área natural e o mundo construído pelo ser humano.

Esfera afetiva - simbolizada pelo amor pela mãe-natureza. Sem ela, a Educação Ambiental perde efetividade, pois, através da esfera afetiva, a pessoa se sensibiliza, para agir em favor do ambiente e de um mundo sustentável.

Domínio técnico - para exercer o desenvolvimento sustentável, não bastam as informações teóricas, ou gostar da questão. Deve-se conhecer formas para transformar a teoria em prática. Por isso, a transmissão deste conhecimento é fundamental, como parte da Educação Ambiental.

\section{O UNIVERSO DE PESQUISA}

\section{CARACTERIZAÇÃO DA CIDADE}

A cidade de São Joaquim da Barra, localizada na Região Norte-Nordeste do estado de São Paulo, cortada por uma das principais vias do estado, a Rodovia Anhanguera a $381 \mathrm{~km}$ da Capital do Estado e está interligada aos principais centros do país, como Goiânia e Brasília; Barretos, São José do Rio Preto e Presidente Prudente pela Rodovia Prefeito Fábio Talarico, possuindo ainda uma vasta malha de rodovias vicinais.

São Joaquim da Barra se localiza a uma latitude 20³4'53 Sul e longitude 4751'17' Oeste, e faz parte da bacia hidrográfica Sapucaí-Mirim/Grande. O relevo da cidade faz parte do planalto Meridional do Brasil e a vegetação floresta tropical com áreas de cerrado que foram substituídos pela agropecuária desde o século passado, restando apenas pequenos

\footnotetext{
${ }^{4}$ Entrevista com o Antonio Jose Rocha - Implantação da Educação Ambiental no Brasil, Brasília - DF, 1998.
} Nucleus, v.8, n.2, out.2011 
capões e matas ciliares. O seu solo é o de terra roxa por ser composto por terrenos arenílticosbasálticos, que favoreceu a agricultura que se desenvolveu inicialmente com o café, algodão, soja e a cana de açúcar.

O município possui uma área de 413,4 km, fazendo limites com as cidades de Guará ao norte-nordeste, Nuporanga ao leste, Orlândia ao sul, Morro Agudo ao sudoeste e Ipuã a oeste.

Na sua economia, destacam se as indústrias de transformação de ferro, siderúrgica e laminação, fabricação de peças para máquinas agrícolas e fabricação de calçados.

As usinas de açúcar e álcool constituem grande parte da economia, gerando para o município boa parte da arrecadação de impostos. O comércio destaca-se pela variedade de atividades tornando a cidade como ponto de referência para a região.

A indústria de esmagamento de soja também tem seu lugar, gerando muitas divisas para o município. As indústrias são grandes geradoras de emprego para a cidade e região. Muitas pessoas também vêm de outros estados em busca de emprego e melhoria de vida.

Sua população estimada em 2009 foi de 46.172 habitantes.

\section{CARACTERIZAÇÃO DAS INSTITUIÇÕES}

Atualmente, a cidade de São Joaquim da Barra atende na rede municipal de Pré-Escola mais de 2.000 alunos sendo 14 pré-escolas e também EMEIS (Escola Municipal de Educação Infantil) em vários bairros; salas de aula em creches municipais e particulares, 4 CEIS, Ensino Supletivo-EJA (Alfabetização de Jovens e Adultos), Escola Técnica de Artes Municipal Fabiano Lozano, Biblioteca de grande acesso para toda a população. A cidade conta também com seis escolas particulares, cursos e atividades livres como línguas, informáica, música, esportes e dança. Encontra-se ainda instalada uma Unidade do Centro Estadual Tecnologico Paula Souza,a Etec Pedro Badran que oferece vários cursos técnicos e ensino médio ao municipio e toda a região. No municipio conta com uma unidade de ensino superior (FACIG) Faculdade de Ciências Gerenciais, com três cursos: Administração, Ciências Contábeis e Turismo.

Em São Joaquim da Barra se encontra também a Diretoria Regional de Ensino que administra 23 escolas em 12 munícipios.

É neste contexto que foram selecionadas duas instituições de ensino para a realização da pesquisa.

A pesquisa foi realizada em duas instituições de ensino públicas e estaduais. A primeira escola denominada de Escola A e a segunda Escola B. As duas instituições se 
encontram em lugares bem diferentes e distantes uma da outra. Foram coletados, analisados, avaliados, os dados dos professores, diretores e coordenadores de cada instituição e também dos alunos. Os questionários têm como a finalidade de investigar a percepção ambiental dos sujeitos e o interesse dos professores em relação ao tema.

A Escola A, possui 30 professores e que atuam no ensino fundamental de $1^{\mathrm{a}}$ a $8^{\mathrm{a}}$ séries com 362 alunos matriculados. Sendo que no perído da manhã as aulas são para os alunos da $5^{\text {a }}$ a $8^{\mathrm{a}}$ série e no período da tarde para os alunos da $1^{\mathrm{a}}$ a $4^{\mathrm{a}}$ série.

A escola $\mathrm{B}$, possui 19 professores que atuam no ensino fundamental sendo que 10 lecionam no turno da manhã e 9 no turno da tarde. Os alunos da escola estão divididos nas turmas do $2^{\circ}$ e $3^{\circ}$ ano e na $3^{\mathrm{a}}$ e $4^{\mathrm{a}}$ série, tolalizano um número de 512 alunos matriculados.

\section{METODOLOGIA E DESENVOLVIMENTO DA PESQUISA}

Para a construção deste trabalho foi feita uma pesquisa para analisar a existência de Educação Ambiental nas escolas.

De acordo com o Tozoni-Reis (2007, p.8-9):

O termo pesquisa significa, segundo o dicionário Aurélio (FERREIRA, 1986), indagação ou busca minuciosa para a averiguação da realidade, investigação e estudo, minudentes e sistemáticos, com o fim de descobrir fatos ou princípios relativos a um campo qualquer do conhecimento. Essas definições ajudam a compreender a pesquisa como uma ação de conhecimento da realidade, um processo d investigação minucioso e sistemático para conhecer a realidade, seja ela natural ou social. O importante aqui é compreender a pesquisa como um processo de produção de conhecimentos para a compreensão de uma dada realidade, isto é conhecimentos que auxiliem na interpretação da realidade.

Esta pesquisa quer compreender e analisar de que maneira as escolas desenvolvem atividades de educação ambiental e como as práticas ambientais podem ajudar os alunos, professores e toda a comunidade escolar a desenvolverem suas percepções, conhecimento e sensibilização, para as questões ambientais.

Para o desenvolvimento da pesquisa foi realizado o levantamento bibliográfico, através de livros, documentos do Ministério da Educação, artigos, pesquisa na internet entre outros a fim de auxiliar na construção da fundamentação teórica como conceitos de educação, educação ambiental e sociedade. Em um segundo momento foram distribuídos questionários como coleta de dados, aos diretores e coordenadores, professores e alunos com a finalidade de investigar se ocorre a prática de educação ambiental e em seguida foi feita a analise destes que foram respondidos com o objetivo de obter informações importantes acerca da percepção ambiental e sensibilização. 
Segundo Tozoni-Reis (2007, p.11), "a pesquisa qualitativa defende a idéia de que na, produção de conhecimentos sobre os fenômenos humanos e sociais, nos interessa muito mais compreender seus conteúdos do que descrevê-los".

Foi realizado junto ao diretor e coordenador um levantamento do Perfil Ambiental de cada instituição para verificar como as escolas estão organizadas no quesito educação ambiental.

A amostragem ocorreu da seguinte maneira: foram distribuídos 17 questionários para os alunos da primeira instituição e 27 para os alunos da segunda, totalizando 44 questionários. Como os questionários das duas instituições obtiveram quase as mesmas respostas optou-se por fazer a análise de dados dos questionários dos alunos das duas instituições junto. Foram distribuídos questionários aos professores das respectivas turmas, sendo um para cada professor.

O processo de análise de dados foi apurado de forma manual sendo utilizados para perguntas fechadas, um padrão de contagem, análise das perguntas abertas e tabelas para as questões de múltipla escolha.

De acordo com Bogdan; Biklen (1994, p. 50).

O processo de análise dos dados é como funil: as coisas estão abertas de inicio (ou no topo) e vão se tornando mais fechadas e especificas no extremo. O investigador qualitativo planeja utilizar parte do estudo para perceber quais são as questões mais importantes. Não presume que se sabe o suficiente para reconhecer as questões importantes antes de efetuar a investigação.

Nas questões aplicadas aos coordenadores pedagógicos buscou identificar como a educação ambiental está inserida no Projeto Político Pedagógico e como a escola trabalha esta questão. O questionário dos professores teve como finalidade identificar como eles trabalham o tema com os alunos e quais são suas expectativas e dificuldades, buscou se verificar como eles definem meio ambiente, educação ambiental e a visão de cada um a respeito dos problemas que causam impactos ambientais e sociais.

Nas questões aplicadas aos alunos procurou-se identificar as práticas pedagógicas, a sensibilização, a percepção e a conscientização que cada aluno já possui.

No primeiro momento foi feito um questionário com o levantamento do perfil ambiental da escola que foi respondido pelo diretor e pelo coordenador pedagógico, com a finalidade de verificar práticas ambientais na escola.

O segundo momento foi realizado através da distribuição dos questionários aos coordenadores, professores e alunos, sendo o questionário compostos de questões dissertativas e de múltipla escolha. 
O questionário de número 1 , aplicado aos coordenadores pedagógicos da escola foi composto de 4 perguntas abertas, visando analisar se a educação ambiental está inserida no currículo da escola.

O questionário de número 2, aplicado aos professores das $4{ }^{\mathrm{a}}$ série composto por 14 questões abertas e também visa investigar o nível de conhecimento e como cada professor trabalha o tema e como eles enxergam a educação ambiental e os problemas ambientais.

O questionário de número 3, aplicado aos alunos das $4{ }^{\text {a }}$ serie , visa investigar o nível de conhecimento das crianças, sua percepção e sensibilização aos assuntos relacionados ao meio ambiente.

\section{ANÁLISE DE DADOS}

\section{ANÁLISE DOS QUESTIONÁRIOS APLICADO AOS COORDENADORES PEDAGÓGICOS}

No questionário dos coordenadores pedagógicos foram analisados e avaliados os questionários modelo em apêndice na qual ficou claro que a escola possui educação ambiental no Projeto Político Pedagógico.

Na escola A, a educação ambiental acontece em parceria com a FAFRAM - Faculdade Dr. Francisco Maeda localizada em Ituverava, localizada em São Joaquim da Barra, na qual desenvolvem os seguintes projetos: Campo Limpo, na qual desenvolvem as seguintes atividades: concurso de desenho e redação, circuitos de palestras sobre assuntos relacionados à preservação do meio ambiente, visitação as centrais de recebimento, atividades culturais e educativas sobre meio ambiente. Sendo realizada com os alunos da $3^{\mathrm{a}}, 4^{\mathrm{a}}, 5^{\mathrm{a}}$ e $6^{\mathrm{a}}$ série que abordou cuidados com o meio ambiente e plantações de árvores pelos alunos e Escola no Campo, com os alunos da $6^{\mathrm{a}}$ série que trabalha sobre pesticidas e o meio ambiente. Os projetos são desenvolvidos em um bimestre da seguinte forma: palestras dos parceiros e após estas, deixam o material e os professores trabalham aprofundando os conhecimentos da criança. Para a escola, a educação ambiental é importante para desenvolver a conscientização dos educandos e para melhorar o dia a dia de cada aluno e da própria escola. A escola não possui área arborizada, mas possui o processo de separação de lixo, que em seguida é vendido para recicladores.

Na escola B, a educação ambiental acontece em parceria com a empresa Mundo Novo ${ }^{5}$ sendo realizado atividades que abrange a organização, preservação e a reciclagem dentro da escola, estando envolvido todos os professores. A dificuldade encontrada pela escola está

${ }^{5}$ Optou-se por usar nomes fictícios ao referir se a empresa envolvida. 
relacionada à falta de interesse dos pais e de alguns alunos em trazerem os materiais que são pedidos para realização das atividades. A escola possui área arborizada que é utilizado para a realização da educação ambiental, mas não possui o processo de separação do lixo produzido pela comunidade escolar, há apenas a separação do lixo orgânico que é buscado pelos vizinhos que são utilizados para a alimentação de porcos e galinhas.

Com o questionário distribuído aos coordenadores pedagógicos, foi possível identificar que as escolas possuem a temática ambiental inserida em seu Projeto Político Pedagógico, e os mesmos acontecem devido à parceria com empresa e com a FAFRAM, sendo de grande importância para as instituições de ensino e também os propostos pela Secretaria do Estado. Além desses projetos, são realizados em datas comemorativas, trabalhos de educação ambiental.

\section{ANÁLISE DOS QUESTIONÁRIOS APLICADO AOS PROFESSORES}

Em relação aos questionários dos professores, pode-se perceber que os professores têm conhecimento em educação ambiental e estão cientes dos problemas ambientais que ocorrem no planeta.

Quanto à primeira questão: Como é trabalhado o tema Meio Ambiente?

O professor da escola $\mathrm{A}$, respondeu que trabalha a educação ambiental através de textos, atividades e aulas expositivas. O professor da escola $\mathrm{B}$, através de leituras, experiências vividas, gibis, jornais, revistas, livros didáticos.

Questão 2: Há material específico?

Escola A: Não, mas trabalha com a prática.

Escola B: Sim, livros, jornais.

Questão 3: Realizam projetos ambientais interdisciplinares?

Os professores das duas instituições responderam que desenvolvem projetos ambientais interdisciplinares.

Em relação à questão 4: É desenvolvido nas escolas projetos ambientais de empresa?

Escola A: Sim.

Escola B: Sim, em parceria com a empresa Mundo Novo.

A questão 5 aborda: Se sim, são bem aceitos?

Escola A: Sim, os alunos sempre participam.

Escola B: Sim.

A sexta pergunta aborda a opinião do professor se a metodologia é adequada. 
O professor da escola A, respondeu que sim, pois há uma interação entre professores e alunos, tendo um bom desenvolvimento e participação de todos os envolvidos.

A questão 7 mostrou qual o entendimento dos professores por educação ambiental. Para o professor da escola A, educação ambiental "é conscientizar os alunos a preservar o meio ambiente para um futuro melhor". Professor da escola B, "para melhorar, salvar a espécie humana precisamos preservar, salvar e aprender a proteger o meio ambiente".

A oitava pergunta: Que assuntos você gostaria de trabalhar a Educação Ambiental na escola?

Os assuntos mais citados foram água, ar, preservação, solo e a vida dos animais com as queimadas.

Os professores entendem que Educação Ambiental é um processo que objetiva o ensino de preservar a natureza.

$\mathrm{Na}$ décima questão observou-se que o professor da escola A tem noção de biodiversidade, dizendo que a mesma abrange toda a variedade de formas de vida, espécie e ecossistemas de uma região, enquanto que o professor da escola $\mathrm{B}$, não respondeu a questão.

Para ambos a água não é um recurso natural inesgotável.

$\mathrm{Na}$ questão 12 foi abordado o que os professores acham a respeito da extinção dos animais.

Para o professor da escola A é um problema muito sério em que os governantes deveriam prestar mais atenção. Já o professor da escola B "uma tristeza, por saber que somos nós os responsáveis".

Em relação à questão 13 que aborda: Qual sua opinião em relação a queimadas e desmatamentos, os professores acham que são uma falta de respeito e conscientização da população e que em relação a queimadas, os animais sofrem, morrem de fome quando não são queimados juntos.

A respeito da décima quarta questão: $O$ que você acha a respeito da miséria, consumismo e desperdício?

O professor da escola A é uma falta de consciência das pessoas que não querem ver o que acontece a sua volta, no seu cotidiano, pensando somente em si mesmas. Para o professor da escola B, acha que tudo é falta de oportunidades e para os que têm conhecimento sofrem com essa situação, e alguns não se preocupam.

\section{ANÁLISE DO QUESTIONÁRIO APLICADO AOS ALUNOS}

A pesquisa foi realizada com alunos de duas turmas matriculada na $4^{\mathrm{a}}$ série, sendo uma 
turma de cada escola. A turma da escola A possuem 17 alunos que cursam o turno da tarde, e os alunos da turma da escola B com 27 alunos que estão cursando o turno da manhã, totalizando 44 questionários entregues e respondidos pelos os alunos. Os alunos estão em uma faixa etária média entre 9 e 10 anos de idade. As questões serão analisadas juntas já que possuem o mesmo grau de respostas.

Em relação à primeira questão: Você acha que cuidar do meio ambiente é importante?

Nessa questão todos os alunos concordaram que é importante cuidar do meio ambiente. Na questão o que significa meio ambiente:

Tabela 1: Percepção ambiental dos alunos.

\begin{tabular}{|c|c|}
\hline $\begin{array}{r}N^{0} \text { de } \\
\text { Alunos }\end{array}$ & Respostas dadas à questão \\
\hline 3 & São apenas paisagens naturais e urbanas. \\
\hline 1 & É tudo o que está relacionado com a paisagem natural: florestas, rios e seus habitats. \\
\hline 1 & É o lugar onde o homem e a natureza estão em constante interação. \\
\hline 6 & $\begin{array}{l}\text { É a inter-relação entre a flora, fauna e o clima, é apenas paisagens naturais e urbanas e } \\
\text { tudo o que está relacionado com a paisagem natural:florestas, rios e seus habitats. }\end{array}$ \\
\hline 2 & $\begin{array}{l}\text { É a inter-relação entre a flora, fauna e o clima e o lugar onde o homem e a natureza } \\
\text { estão em constante interação. }\end{array}$ \\
\hline 6 & $\begin{array}{l}\text { Tudo o que está relacionado com a paisagem natural: florestas, rios e seus habitats e o } \\
\text { lugar onde o homem e a natureza estão em constante interação. }\end{array}$ \\
\hline 1 & Meio ambiente é a relação de todas as alternativas \\
\hline 11 & É a inter-relação entre flora, fauna e o clima. \\
\hline
\end{tabular}

$\mathrm{Na}$ terceira questão que aborda a relação com a natureza, as crianças responderam da seguinte maneira:

Tabela 2: Relacionamento com a natureza

\begin{tabular}{cl}
\hline $\begin{array}{c}\mathbf{N}^{\mathbf{0}} \text {. de } \\
\text { alunos }\end{array}$ & \multicolumn{1}{c}{ Respostas dadas à questão } \\
\hline 4 & são amigos das árvores. \\
1 & não joga lixo no chão. \\
1 & $\begin{array}{l}\text { não se preocupa com a natureza, pois mora na cidade e não tem muitos animais e } \\
\text { plantas. }\end{array}$ \\
7 & cuidam dos animais e das plantas e são amigos das árvores. \\
14 & cuidam dos animais e das plantas, são amigos das árvores e não jogam lixo no chão. \\
6 & cuidam dos animais e das plantas e não jogam lixo no chão. \\
2 & não jogam lixo no chão e não se preocupam com a natureza, pois moram na cidade e \\
& não tem muitos animais e plantas. \\
9 & cuidam dos animais e das plantas.
\end{tabular}


Na quarta questão sobre ser ecológico, as respostas ficaram assim:

Tabela 3: Ser ecológico

\begin{aligned} $\begin{array}{c}\mathbf{N}^{\mathbf{0}} \mathbf{. d e} \\ \text { alunos }\end{array} & \multicolumn{1}{c}{$ Respostas dadas à questão } \\ \hline 8 & $\begin{array}{l}\text { desligam a torneira quando estão escovando os dentes } \\ \text { não se preocupa com o desperdício da água. }\end{array} \\ 5 & \begin{array}{l}\text { não se deve desperdiçar água. } \\ \text { respeitar os outros, os animais e plantas, desligar a torneira quando estiverem escovando } \\ \text { os dentes e não desperdiçarem água. }\end{array} \\ 7 & \begin{array}{l}\text { respeitar os outros, os animais e desligar a torneira quando estiverem escovando os } \\ \text { dentes }\end{array} \\ 1 & \begin{array}{l}\text { respeitar os outros, os animais e plantas e não desperdiçar água. } \\ \text { desligar a torneira quando estiver escovando os dentes e não desperdiçar água. }\end{array} \\ 11 &$ disseram que ser ecológico é: respeitar os outros, os animais e plantas. \end{aligned}

$\mathrm{Na}$ quinta questão, a respeito da água potável, se pode acabar, 36 crianças responderam que sim, enquanto que 8 crianças responderam que não.

A sexta questão aborda se o lixo é ou não separado em casa, 32 disseram que há separação do lixo em suas casas, e 12 responderam que não separam lixo em sua casa.

Todas as crianças responderam que perto de suas casas não há nenhum riacho, que se refere a sétima questão.

$\mathrm{Na}$ oitava questão que aborda se os problemas ambientais, como desmatamento, poluição, extinção de animais estão cada vez mais sendo discutidos na mídia e na sociedade, 18 crianças responderam que isso é ruim ou péssimo, enquanto que 25 acham que é ótimo ou importante.

A questão de número 9 teve como objetivo constatar se os professores abordam algum problema ambiental na sala de aula e quais assuntos se a resposta fosse positiva.

As crianças disseram que os seus professores abordam os problemas ambientais como: preservação, cuidar do meio ambiente, animais e plantas que extinção, assim como água, poluição, lixo, desmatamentos. E usar de maneira consciente a água desligando a torneira ao escovar os dentes, não desperdiçando. Assuntos como reciclagem, preservação são abordados pelos professores. Os alunos deixaram claro que as empresas envolvidas trabalham muito o tema meio ambiente.

A questão número 10 se refere a ação dos alunos "se próximo a casa deles, ou na cidade houvesse um rio ou córrego, e este se encontra cheio de lixo jogado pelas pessoas, qual seria a iniciativa deles". 
Tabela 4: Conscientização ambiental

\begin{tabular}{cl}
$\begin{array}{c}\mathbf{N}^{0} . \text { de } \\
\text { alunos }\end{array}$ & \multicolumn{1}{c}{ Respostas dada a questão } \\
\hline 29 & Conversariam com os moradores para não jogarem lixo no rio ou no córrego \\
11 & $\begin{array}{l}\text { Conversariam com os moradores para não jogarem lixo no rio ou no córrego } \\
\text { Entram em contato com algum setor público para remover o lixo do rio ou córrego }\end{array}$ \\
3 & Entram em contato com algum setor público para remover o lixo do rio ou córrego \\
1 & Não respondeu a questão \\
\hline
\end{tabular}

Na questão de número 11 foi abordado qual seria a atitude das crianças se ela visse um colega caçando, um pássaro. As respostas ficaram assim:

Tabela 5: Sensibilidade ambiental

\begin{tabular}{ll}
$\begin{array}{l}\mathbf{N}^{\mathbf{0}} \text {. de } \\
\text { Alunos }\end{array}$ & \multicolumn{1}{c}{ Respostas dadas à questão } \\
\hline 11 & Diriam que temos que respeitar a natureza e tudo o que nela existe. \\
2 & $\begin{array}{l}\text { Ficariam tristes. } \\
\text { Conversariam com ele para não fazer mais isso e diriam que temos que respeitar a natureza e }\end{array}$ \\
3 & $\begin{array}{l}\text { tudo o que nela existe. } \\
\text { Conversariam com ele para não fazer mais isso, diriam que temos que respeitar a natureza e } \\
\text { tudo o que nela existe e ficaria triste. }\end{array}$ \\
18 & Conversariam com ele para não fazer mais isso \\
\hline
\end{tabular}

A questão número 12 se refere sobre a percepção dos alunos, se elas acham que a exposição ao sol sem proteção pode causar câncer de pele em horários inadequados. As respostas ficaram da seguinte maneira: 36 alunos disseram que sim e 6 não.

Na questão número 13 teve como finalidade constatar se eles são amigos de alguma arvore ou de algum animal. As respostas ficaram dessa maneira: 41 disseram que sim, 2 não e 1 criança não respondeu a questão.

Nas próximas questões (número 14 e 15) abordou-se com as crianças se elas fossem um animal ou arvore qual elas seriam. Em seguida foi perguntado se esse animal ou árvore estivesse em extinção o que elas fariam.

A respeito da primeira pergunta as crianças responderam desde animais domésticos, pássaros a animais selvagens. Em relação a próxima pergunta elas responderam que alguns levariam para casa, cuidariam, fariam protesto, abaixo assinado, não deixariam cortar as árvores,buscariam lugares seguros e plantariam mais árvores. Uma criança não respondeu nada e quatro não responderam as questões.

\section{INTERPRETAÇÃO DOS DADOS}

A educação ambiental é extremamente importante para todo o ser humano e para a sociedade. Através dela o homem pode-se conhecer melhor, se avaliar, analisar suas atitudes, 
decisões e compreender que a população humana no decorrer do tempo tem causado grandes danos ao ambiente.

De acordo com Dias (2004), dessa maneira a educação ambiental é o modo mais adequado que se tem de promover uma educação que esteja de acordo com a realidade, necessidades, problemas e aspirações de cada indivíduo e das sociedades do mundo atual.

Pois se pode afirmar que os problemas ambientais não ameaçam apenas o futuro físico do planeta como questionam o futuro de valores da sociedade apontando para a necessidade de uma profunda mudança e reorientação nos modos de conhecer e de como se relacionam com a natureza.

Em relação aos questionários dos professores buscou verificar a prática dentro da sala de aula através das questões de $\mathrm{n}^{\circ} 1$ ao $\mathrm{n}^{\circ} 6$. Ficou constatado que os professores trabalham a educação ambiental dentro da sala de aula com o material que é fornecido pelos parceiros e também abordam a temática em datas comemorativas e quando é sugerido algum projeto pela Secretaria do Estado. Um dos professores deixa claro que sente uma necessidade de aprofundar mais no tema referente às queimadas. Os professores integram os acontecimentos diários da sala de aula com a temática ambiental.

As questões abordaram também sobre o conhecimento dos professores acerca de temas como educação ambiental, biodiversidade, recursos naturais e problemas ambientais. Verificou também que os professores vêm na educação ambiental a preservação do meio ambiente e da espécie humana para um futuro melhor.

De acordo com Dias (2004), a educação ambiental deve prover aos indivíduos e a comunidade meios de percepção e compreensão dos fatores que interagem no tempo e no espaço, tendo a consciência do meio ambiente, ao mesmo tempo em que adquirem conhecimento, valores e habilidades e os tornem aptos a resolverem os problemas ambientais presente e futuros, e também ajudar a definir novos padrões de comportamentos para a melhoria do meio ambiente. Não se esquecendo de se levar em conta às realidades econômica, social e ecológica de cada sociedade.

Nas três ultimas questões, foi possível verificar que os professores têm noção dos temas abordados e que estão conscientes que esses problemas ambientais são o resultado das atividades humanas e do mau relacionamento do homem com a natureza e com a sociedade.

Segundo o PCN - Meio Ambiente e Saúde (1997, p.47),

A opção pelo trabalho com o tema Meio Ambiente traz a necessidade de aquisição de conhecimento e informação por parte da escola para que possa desenvolver um trabalho adequado junto aos alunos. Pela própria natureza da questão ambiental, a aquisição de informações sobre o tema é uma necessidade constante para todos. Isso não significa dizer que os professores deverão "saber tudo" para que possam 
desenvolver um trabalho junto dos alunos, mas sim que deverão se dispor a aprender sobre o assunto e, mais do que isso, transmitir aos seus alunos a noção de que o processo de construção e de produção do conhecimento é constante.

No questionário dos alunos procurou verificar o aprendizado das crianças em relação ao meio ambiente, a percepção que elas já possuem em relação aos problemas ambientais e a sensibilidade, pois é através desta que os alunos estarão mais abertos a novas posturas solidárias e éticas em relação ao meio ambiente.

Os alunos sentem que cuidar do meio ambiente é importante, e que o homem faz parte desse ambiente. $\mathrm{O}$ contato das crianças com a natureza acontece muitas vezes quando são amigas de algum animal ou árvore. Nessa questão buscou evidenciar a sensibilidade e o cuidado que elas possuem com a natureza e os seus elementos, inclusive não jogar lixo no chão. Aqui se percebe que as crianças possuem a percepção do que essa atitude pode ocasionar se não for feita e como pode ocasionar muitos problemas ambientais. Através dessa questão pode se verificar o trabalho dos professores dentro da sala de aula e como as crianças já conseguem assimilar o que aprendido em sala de aula com aquilo que lhe são propostos.

Para uma criança isso não foi possível à assimilação e a compreensão da dimensão da educação ambiental global, ela se limitou apenas ao seu espaço que é a cidade e como aqui não possui muitos animais e plantas ela não vê a necessidade de se preocupar com a natureza.

Os alunos já possuem uma visão do que é ser ecológico, não se restringindo a apenas uma alternativa, mas tem a dimensão de que envolvem outras alternativas, levando-os a perceberem que é fazer diversas coisas que parecem ser simples. Mas é dessa maneira que as crianças começam a ter a noção do todo e através do respeito ao outro, elas conseguem ter a dimensão da diversidade social, que independente de sua raça, crenças, valores, cultura.

De acordo com o PCN - Meio Ambiente e Saúde (1997, p. 57):

A questão ambiental, no ensino de primeiro grau, centra-se principalmente no
desenvolvimento de valores, atitudes e posturas éticas, e no domínio de
procedimentos, mais do que na aprendizagem de conceito, uma vez que vários dos
conceitos em que o professor se baseará para tratar os assuntos ambientais
pertencem às áreas disciplinares.

Segundo Dias (2004), o bem estar e a sobrevivência da humanidade dependem de cada um, e de como as pessoas são capazes de atribuírem o respeito e a consideração por aqueles que são menos favorecidos, que necessitam mais de conhecimentos, de informações para lutar por seus direitos: à vida, a moradia, saúde, a um ambiente que garanta a sua qualidade de vida.

A maioria dos alunos possui a noção que a água pode acabar sendo necessário usá-la de forma consciente e não desperdiçá-la. Sabe da necessidade de se separar o lixo, mas 
afirmam que essa não é uma prática constante em suas casas. Seria necessário que houvesse um trabalho da escola junto á comunidade.

Muitos alunos acham que é importante a discussão dos problemas ambientais, podendo constatar que o professor terá maior facilidade em trabalhar temáticas ambientais que demonstram interesse ao aluno.

Observa-se que os alunos têm a noção do perigo que é jogar lixo no rio ou no córrego, e se preocupam e tentam buscar soluções para este problema. Percebe-se que os alunos estão começando a entender a necessidade da participação deles como agentes de mudanças na solução de problema locais. E que os alunos se preocupam com a natureza e com as atitudes do colega quando tentam impedir que eles matem o pássaro, assim como tem noção do perigo que é de se expor ao sol sem a devida proteção.

\section{CONSIDERAÇÕES FINAIS}

Após analisar os questionários, constatou-se que a educação ambiental está inserida no currículo da escola. Os questionários formulados e analisados buscaram averiguar como está desenvolvida essa educação ambiental nas duas instituições de ensino. Através dos questionários foi possível verificar que as escolas estão em fase de adaptação. Os projetos desenvolvidos demonstram que as escolas estão começando a se organizar para a prática da educação ambiental e que a escola está aberta a mudanças e transformações que visam à melhoria da qualidade da comunidade escolar e local.

Percebe-se também que os alunos são capazes de identificar as questões ambientais e que muitas vezes relacionam o que sabem com aquilo que lhes foi proposto para estudo pelos parceiros envolvidos e o que é realizado em datas comemorativas.

Sabe-se que a problemática ambiental está cada vez mais sendo discutida nos meios de comunicação, cabendo ao educador, desenvolver na educação formal, um trabalho permanente de sensibilização, percepção e conscientização das questões ambientais. É necessário também que as escolas busquem maneiras para inserir os pais na prática da escola e também buscando meios para que os assuntos trabalhados em sala de aula tenham eficiência nas casas dos alunos.

Pode-se constatar que a educação tem sido significativa contribuindo para a construção da conscientização das crianças.

É necessário que as escolas também comecem a desenvolver práticas dentro das escolas e se envolvam mais na questão ambiental, produzindo trabalhos que envolvam mais a realidade das crianças, suas culturas. Sendo importante que passem a abordar as questões 
relativas à educação ambiental como consumismo, economia, política, sociedade para que os alunos se tornem cidadãos críticos capazes de identificar problemas ambientais interligando esses fatores com os fatos que acontecem a todo instante, não ficando apenas restrito a ecologia, mas que sejam capazes de relacionar todos esses aspectos.

É importante o trabalho da escola no desenvolvimento de cidadãos socioambientais, pois ela marca muito a trajetória de qualquer pessoa. Á medida que esses ensinamentos vão se enraizando nas crianças, mais elas terão noção do que é ser um cidadão, e seus atos serão conscientes e não apenas algo superficial. Serão pessoas críticas com a realidade que as envolve, mas ao mesmo tempo sensíveis às mazelas do mundo, tendo uma percepção aguçada a respeito dos acontecimentos, capazes e identificar problemas ambientais, tomar iniciativas e buscar soluções.

Além do que contribuirão para a preservação e manutenção da vida no planeta, para um desenvolvimento sustentável, um consumo consciente e para a construção da solidariedade, pensando nas gerações futuras e não somente em si próprias.

O mundo da maneira que está pode ser mudado, não dando para reverter muitas ações, mas para minimizar as reações do mau relacionamento que o homem manteve com a natureza no decorrer da história, nunca é tarde para mudanças de comportamento e novas atitudes. Se cada um fizer a sua parte é sinal que a mudança já começa a ocorrer dentro de nós mesmos.

Os educadores têm a responsabilidade de construir uma sociedade que satisfaça as exigências presentes e que garanta a sobrevivência de valores como o respeito ao planeta, ao próximo e à dignidade humana de cada indivíduo.

\section{REFERÊNCIAS}

ALVES, D. Sensopecepções em ações em educação ambiental. Brasília. Ministério da Educação e do Desporto - MEC. Instituto Nacional de Estudos e Pesquisas Educacionais. Série documental: Antecipações, nº7.out. 1995.

BOGDAN, R.C. ; BIKLEN, S.K. Investigação qualitativa em educação. Portugal: Porto Editora, 1994.

BUSQUETS, M.Det al. Temas transversais em educação: bases para uma formação integral. 6.ed. São Paulo: Ática, 2008.

CAMPO LIMPO. Disponível em: http://www.dianacionaldocampolimpo.org.br/inicial.aspx. Acesso em: 10 out.2010.

CARVALHO, I.C.M. Em direção ao mundo da vida: interdisciplinaridade e educação ambiental. Brasília: IPÊ- Instituto de Pesquisas Ecológicas, 1998. 
CAVALHEIRO, J.S. Consciência ambiental entre professores e alunos da Escola

Estadual Básica Dr. Paulo Devanier Lauda. Santa Maria, RS:UFM-RS, 2008.

CUNHA,S.B e GUERRA, A.J.T (org.). A questão ambiental: diferentes abordgens. 4.ed. Rio de Janeiro: Bertrand Brasil, 2008.

DIAS, G.F. Educação ambiental: princípios e práticas. 9.ed. São Paulo: Gaia, 2004.

GADOTTI,M. Pedagogia da Terra. São Paulo: Peirópolis, 2000 (Série Brasil Cidadão).

LA TAILLE,Y. et al. Piaget, Vgotsky, Wallon: teorias psicogenéticas em discussão. São Paulo:Summus, 1992.

LIBÂNEO, J.C. Didática. São Paulo: Cortez, 1994.

MINISTÉRIO DA EDUCAÇÃO E DO DESPORTO. A implantação da educação ambiental no Brasil.1.ed. Coordenação de Educação Ambiental, 1998.

MINISTÉRIO DA EDUCAÇÃO E DO DESPORTO. Panorama da educação ambiental no ensino fndamental. Brasília, DF, 2001.

MINISTÉRIO DA EDUCAÇÃO E DO DESPORTO. SECRETÁRIA DE EDUCAÇÃO FUNDAMENTAL. Parâmetros Curriculares Nacionais: meio ambiente, saúde, 1997.

PEDRINI, A. G. (org.). Educação ambiental: reflexões e práticas contemporâneas. 6. ed. Petrópolis, RJ: Vozes, 2008. (Coleção Educação Ambiental).

RODRIGUES,L. Especialização em educação ambiental e ensino formal. Vale do Juruena: IES - Instituto superior de educação do Vale do Juruena.

SÃO JOAQUIM DA BARRA. Disponível em:

htpp://www.saojoaquimdabarra.sp.gov.br/acidade/html. Acesso em: 10 out.2010.

SAVIANI,D. A nova lei da educação: trajetórias, limites e perspectivas. 10.ed. Campinas, SP. Autores Associados, 2006.

SECRETÁRIA DO MEIO AMBIENTE. Educação ambiental: o que se pensa, o que se faz. Governo do Estado de São Paulo.

TOZONI-REIS, M.F.C. Metodologia da pesquisa científica.2.ed. Curitiba: IESDE Brasil SA, 2007.

VIGOTSKI, L.S. A formação social da mente. 7. ed. São Paulo: Martins Fontes, 2008

VILLELA,M; PARRA, M. Uma introdução à educação ambiental. Revista Diálogos e Saberes. Mandaguari, v.1, n.2. p.9-15, 2004. 